\title{
USING ASSISTIVE TECHNOLOGY TO ENHANCE TEACHING FOR STUDENTS WITH AUTISM SPECTRUM DISORDERS
}

\author{
Akram Radwan $^{1 *}$ and Zehra Cataltepe ${ }^{2}$ \\ ${ }^{1}$ Computer Engineering Department, Istanbul Technical University, Istanbul, Turkey, email: \\ aradwan@itu.edu.tr, zehra@tazi.io \\ ${ }^{2}$ Tazi.io, Istanbul Technical University, Istanbul, Turkey \\ ${ }^{*}$ Corresponding author
}

\begin{abstract}
Most people with autism spectrum disorders (ASD) have some degree of a learning disability. Hence, students with ASD cannot learn in the same way as typically developing children do and they need special treatment to learn a concept. The purpose of this paper is to use assistive technology to enhance teaching object recognition for students with ASD and then get a better understanding of how they learn and categorize the objects. For this purpose, a web and touch-based application was developed for teaching object recognition in images where objects were grouped according to five categories and four difficulty levels. Due to several features for tablet PC, the study suggests that the tablet is an effective educational tool to enhance teaching and learning for students with ASD. The software allows us to analyze the data gathered during the learning sessions and make useful decisions about the teaching process. Based on our findings, we offer suggestions that may help in future applications that can be developed for students with ASD.
\end{abstract}

Keywords: Autism Spectrum Disorders, Object Recognition, Concept Teaching, Assistive Technology,

\section{INTRODUCTION}

Autism spectrum disorder (ASD) refers to a group of complex neurodevelopment disorders. ASD is characterized by significant impairment in some areas of functioning, including social interaction, verbal and nonverbal communication, social imagination and repetitive behaviours (American Psychiatric Association, 2013). Autism is often associated with a learning disability. Most people with ASD, nearly $70 \%$, have some degree of a learning disability based on the individual's IQ score and level of cognitive functioning (Jordan, 2013). Hence, children with ASD cannot learn in the same way as most people and they need special treatment to learn a concept or object.

Categorization allows mapping of objects from high dimensional and continuous domains to a smaller number of discrete values. This simplification reduces demands on memory and reduces the complexity of the human's environment (Gastgeb, Dundas, Minshew, \& Strauss, 2012). Categorization of objects introduces challenges to children with ASD, especially when it is based on complex features 
that are less apparent than simple features such as color or size (Klinger \& Dawson, 1995). Gastgeb, Strauss \& Minshew (2006) examined whether individuals with ASD have difficulty categorizing common objects and whether their categorization abilities are affected by the typicality of objects. The authors found that individuals with ASD can easily categorize objects when the task involves simple and typical objects but they have some difficulty when categorization involved more complex or less typical objects.

Several studies show that computers and other technological devices are the preferred medium that provide a motivated learning process to most individuals with ASD (O'Malley, Lewis \& Donehower, 2013; V. Smith \& Sung, 2014). In comparison to traditional programs, teaching that uses software presented on computers or tablets were shown to increase attention and desire to learn for students with ASD.

In recent years, many empirical studies utilized a tablet or iPad as learning tools in educational program for students with ASD. Kagohara et al. (2012) aimed to teach two students with ASD to check the spelling of words using the spell-check function on common word processor programs. The results indicated that video-modeling intervention on an iPad improved teaching spelling skills to the children. Two children (aged 3 and 7) showed an increase in academic engagement and decrease in problem behaviors when teaching was delivered using an iPad compared to using a traditional approach in (Neely, Rispoli, Camargo, Davis \& Boles, 2013). Smith, Spooner \& Wood (2013) investigated the effect of the present slideshows on a tablet to teach science terms to three adolescents with ASD. All students generalized new terms to activity sheets. Teachers and students agreed that the tablet was an effective and appropriate teaching tool. Doenyas et al. (2014) performed the first study on three Turkish children with ASD to observe their reactions to the tablet application and its effectiveness in teaching sequencing skills. In this study, all participants demonstrated improvement from initial to the final testing sessions. However, the application was not enough to teach the skills to youngest boy, who required external help, and it was so easy for the oldest boy, who did not use the rewards and he got bored early.

Our study attempts to expand previous research by using a tablet PC with a web-based application for teaching students with ASD. We developed a web and touch-based application for teaching students different objects using visual and audio features and measure students' learning progress. The software allows us to analyse the data gathered during the learning sessions and make useful decisions about teaching process.

\section{METHOD}

\subsection{Participants}

Five students ( 1 female, 4 males) with mild to moderate levels of ASD participated in this study. Participants' ages ranged from 5 to 9 years (mean $=7.16, S D=1.1)$. The participants were recruited from two schools in Gaza-Palestine that provide education for students with ASD. We selected eligible participants based on the following criteria: (a) diagnosed with ASD; (b) having no other disabilities; (c) attending school regularly (five days a week); and (d) being able to remain seated for 15-20 minutes while engaged in an activity.

\subsection{Materials}

We chose five common categories for a real-world dataset: fruits, vegetables, animals, tools for eating \& cleaning and furniture. For each category, we picked six objects. These objects represented the most common categories of concrete objects in the daily life of a child. Picture stimulus of target objects were coloured images and they were collected using image search engines. Every object class contained about 30 different images. We used an attribute-based approach (Farhadi, Endres, Hoiem, \& Forsyth 2009) to select levels of difficulty as follows: L1: color, L2: shape or cross-section, L3: pattern or material and L4: function (see Fig. 1a). These difficulty levels may be similar with some categories and differ with others. For example, cross-section attribute was used with L2 for fruits and vegetables but could not be used with the rest of the categories. Indeed, levels of difficulty did not have strict definitions and they depend on the nature of category. In order to measure the ability of students to generalize (i.e. they do not memorize a particular picture, but learn the concept), different images were used for each session. Moreover, the images used for teaching and assessment conditions of the same session should be different, otherwise over-fitting could occur (Alpaydin, 2014). 


\subsection{Experimental Design and Procedures}

This study employed the single subject research methodology (Horner et al., 2005). An AB design was used with two phases: baseline (consisted of only assessment condition) and intervention (consisted of teaching condition followed by assessment condition). Ten sessions of each phase were performed for each participant. The teaching procedure was based on the Applied Behavioral Analysis (ABA) principles (Alberto \& Troutman, 2012) which has shown effectiveness in teaching skills to individuals with ASD (Eldevik et al., 2013). The application was designed and built as a web-based application. That design decision allowed for more flexibility to access the application from anywhere and using any device (laptop, tablet, or mobile). The application was presented on a tablet PC (see Fig. 1d).

a)

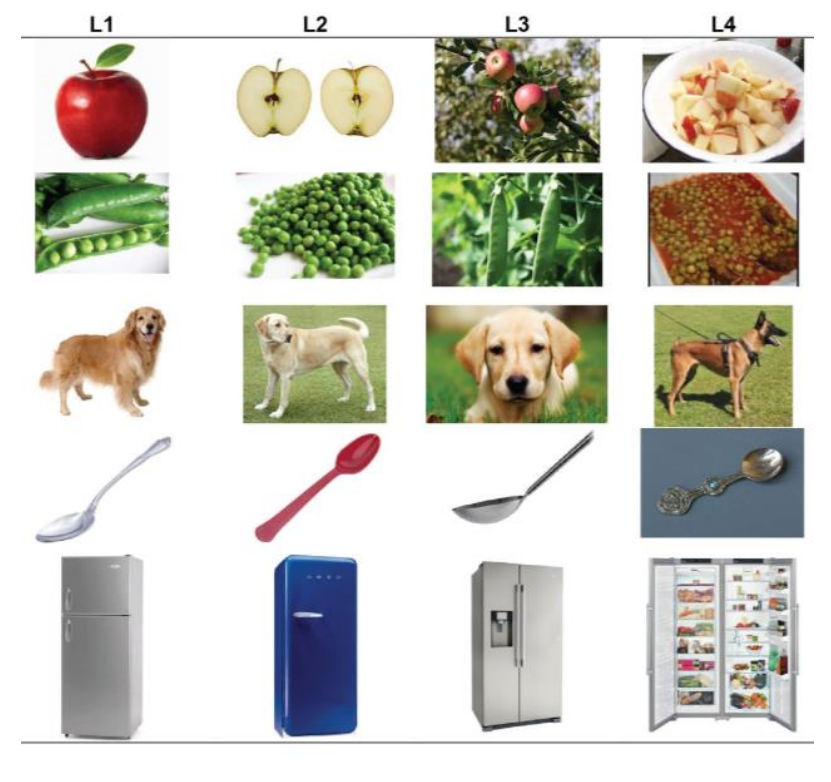

b)

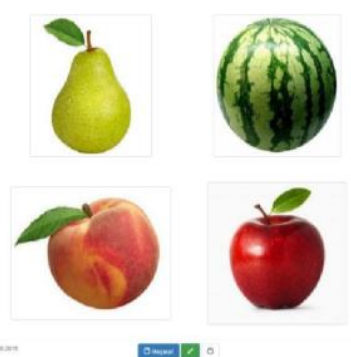

d)

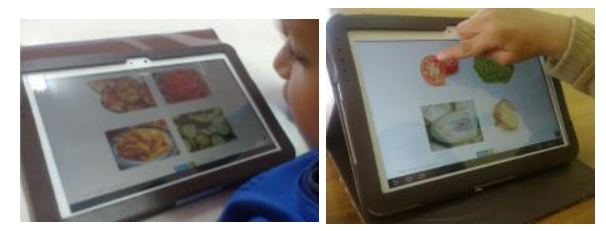

Fig. 1 a) A sample of images from the dataset used for teaching and assessment conditions. b) Screen display of assessment trial. c) The reward screen for the correct answer in a teaching trial. d) A participant interacting with our application during the conduction of the investigation.

In an assessment trial, the application firstly presented a set of four objects (e.g., images of an apple, peach, pear and watermelon) on the tablet's screen as shown in Fig. 1b. Second, the participant immediately heard an auditory stimulus through the tablet (e.g., "apple" or the function of the object e.g., "for eating rice, we use?"). Third, the student engaged in a response (e.g., pointing to or touching the picture on the screen of the tablet). Student was encouraged to respond as quickly as possible and did not receive any feedback on the accuracy of his response.

In a teaching label trial, the application started in a way which is similar to that in the assessment trail. If the student chose a correct answer, the application gave visual (smileys) and an acoustical reinforcement (applause) to reward learning as shown in Fig. 1c. If the given answer was incorrect, the application gave a certain acoustical sound to indicate the wrong answer and the student was asked to try again. An incremental cue was presented by shaking the correct answer horizontally two times in order to help the student. If the student's response was again incorrect, he was then given another opportunity to answer by shrinking three distractors in order to emphasize the correct answer. Finally, if the student could not answer correctly, correct answer was given and shown on the tablet's screen.

\subsection{Dependent Measures}

Two dependent variables were used: the percentage of correct responses (accuracy) and mean response time (RT). The measurements were recorded automatically by the application. The number of auditory stimulus repeats (AR) was also recorded. When comparing two or more conditions, the condition with high accuracy and low mean RT will be the best in overall performance. But when the condition with faster response has lower accuracy or vice versa, it is difficult to reach a convincing conclusion. The inverse efficiency score (IES) is a way to combine both measures (accuracy and correct response time) (Bruyer \& Brysbaert, 2011) and it is commonly used in case of speed-accuracy trade-off. The IES is calculated by dividing correct response time by accuracy within condition; a lower 
score means better performance. The collected data was analyzed using statistical packages $\mathrm{R}$ Commander (Rcmdr) v2.1-7 (Fox \& Carvalho, 2012).

\section{RESULTS AND DISCUSSION}

Table 1 gives the comparison of participants' mean responses over all sessions. Participant 3 has the best performance in terms of accuracy and RT. IES is better to identify to the overall performance for other participants. According to Fig. 2 with Table 1, when the accuracy is considered, participant 1 and 3 performed the best with respect to accuracy (92.9\% and 93.9\%, respectively) and mean RT (4.807 and 4.541, respectively). They have the highest accuracy and lowest mean RT while Participant 2 performed the worst. Participant 4 and 5 have the average performance. On the other hand when the IES is considered, participants respective performance change for some participants.

Table 1. The performance of participants. Mean response times (RT); mean of correct response times (PRT); mean of incorrect response times (NRT); inverse efficiency score (IES); percentage of auditory repeats (AR); number of trials (NT); student's overall performance. Standard error of the means are given in parentheses.

\begin{tabular}{|c|l|l|l|l|l|l|l|l|}
\hline $\begin{array}{l}\text { Participant } \\
\text { ID }\end{array}$ & $\begin{array}{l}\text { Accuracy } \\
(\%)\end{array}$ & $\begin{array}{l}\text { RT } \\
(\mathrm{sec})\end{array}$ & $\begin{array}{l}\text { PRT } \\
(\mathrm{sec})\end{array}$ & $\begin{array}{l}\text { NRT } \\
(\mathrm{sec})\end{array}$ & $\begin{array}{l}\text { IES } \\
(\mathrm{sec})\end{array}$ & $\begin{array}{l}\text { AR } \\
(\%)\end{array}$ & $\begin{array}{l}\text { No of } \\
\text { trials }\end{array}$ & $\begin{array}{l}\text { Overall } \\
\text { Performance }\end{array}$ \\
\hline 1 & $0.929(0.011)$ & $\begin{array}{l}4.807 \\
(0.157)\end{array}$ & 4.474 & 8.574 & 4.812 & 0.118 & 570 & best \\
\hline 2 & $0.766(0.016)$ & $\begin{array}{l}8.162 \\
(0.291)\end{array}$ & 7.566 & 10.110 & 9.881 & 0.236 & 700 & worst \\
\hline 3 & $0.939(0.011)$ & $\begin{array}{l}4.541 \\
(0.157)\end{array}$ & 4.167 & 9.822 & 4.439 & 0.065 & 490 & best \\
\hline 4 & $0.828(0.014)$ & $\begin{array}{l}4.761 \\
(0.133)\end{array}$ & 4.467 & 6.179 & 5.394 & 0.121 & 710 & average \\
\hline 5 & $0.853(0.014)$ & $\begin{array}{l}10.314 \\
(0.353)\end{array}$ & 9.269 & 11.425 & 10.863 & 0.187 & 620 & worst \\
\hline
\end{tabular}
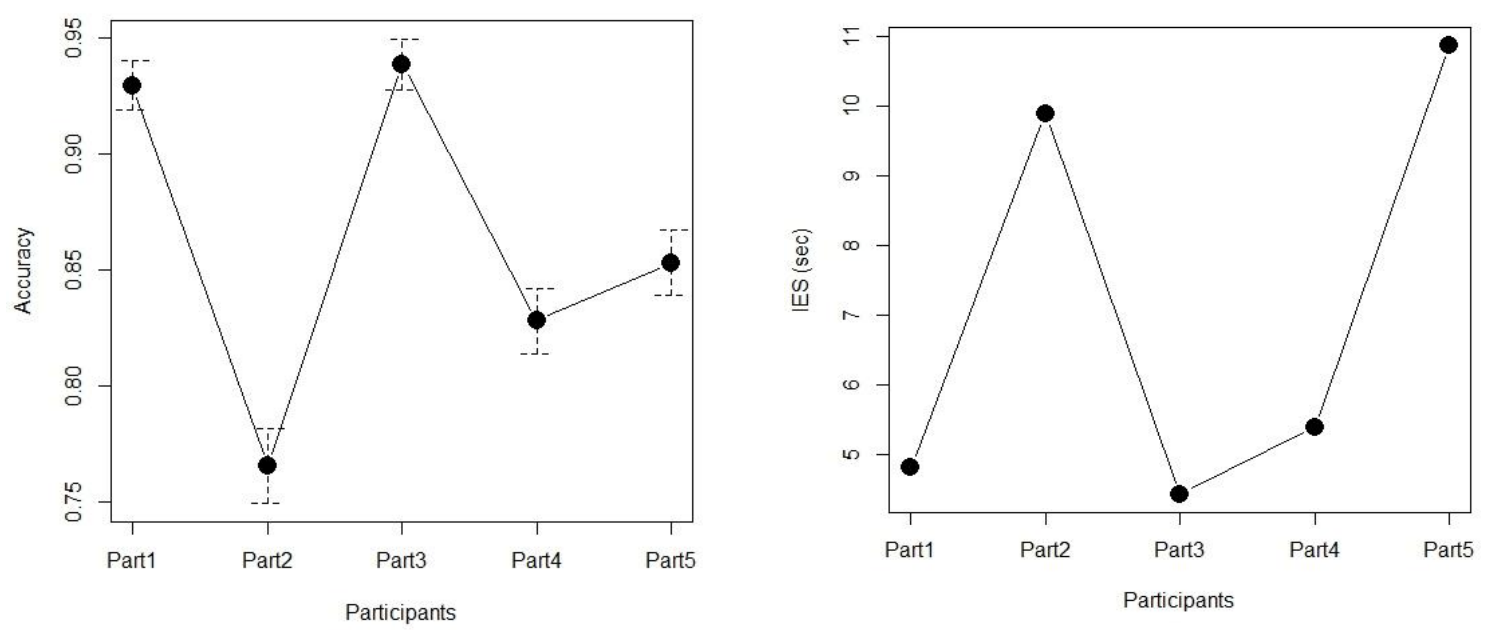

Fig. 2. The performance of the participants in terms of accuracy and inverse efficiency score (IES).

\subsection{Relationships between variables}

Multiple linear regression analyses over 3090 trials of all five participants was conducted to test the correlations among three variables; response time as the dependent variable with accuracy and auditory repeats as the independent variables. This analysis revealed a strong negative correlation between response time and accuracy, $\beta=-3.19 ; p<0001$; whereas a significant positive correlation between response time and auditory repeats, $\beta=8.95 ; p<0001$. In other words, the higher participants' accuracy, the faster they were, and the higher participants' auditory repeats the slower they were. Fig. 3 shows the model residuals against the fitted values. The red line drawn on the plot is a linear least-squares fit the model. As predicted, there was a negative correlation between accuracy and auditory repeats, $\beta=-0.123 ; p<0001$, i.e., the higher student's accuracy is, the fewer auditory 
repeats student needs. In sum, the regression analyses matched the overall results we summarized in Table 1.

\subsection{The effectiveness of difficulty levels}

Fig. 4 shows that as the difficulty level gets higher, the students make more mistakes and respond slower. These findings support that our selection of the difficulty level was correct, and that the images used for these levels were appropriate. Hence, the color is the simplest attribute to discriminate the objects while the function attribute is the hardest one. Compared to levels (L1-L3), we noted that all participants performed worse and responded more slowly at L4 (Fig. 4). Thus, they should be taught more about the function of the objects. We highly recommend students' educators to make a link between the objects and their use in the student's life. Since the drop in accuracy and RT is more from $L 3$ and $L 4$ than from $L 1$ to $L 2$ and $L 2$ to $L 3$, we conclude that the relative difficulty of level $L 4$ respect to level $L 3$ is more that the relative difficulty of level $L 2$ to $L 1$ and level $L 3$ to $L 2$.

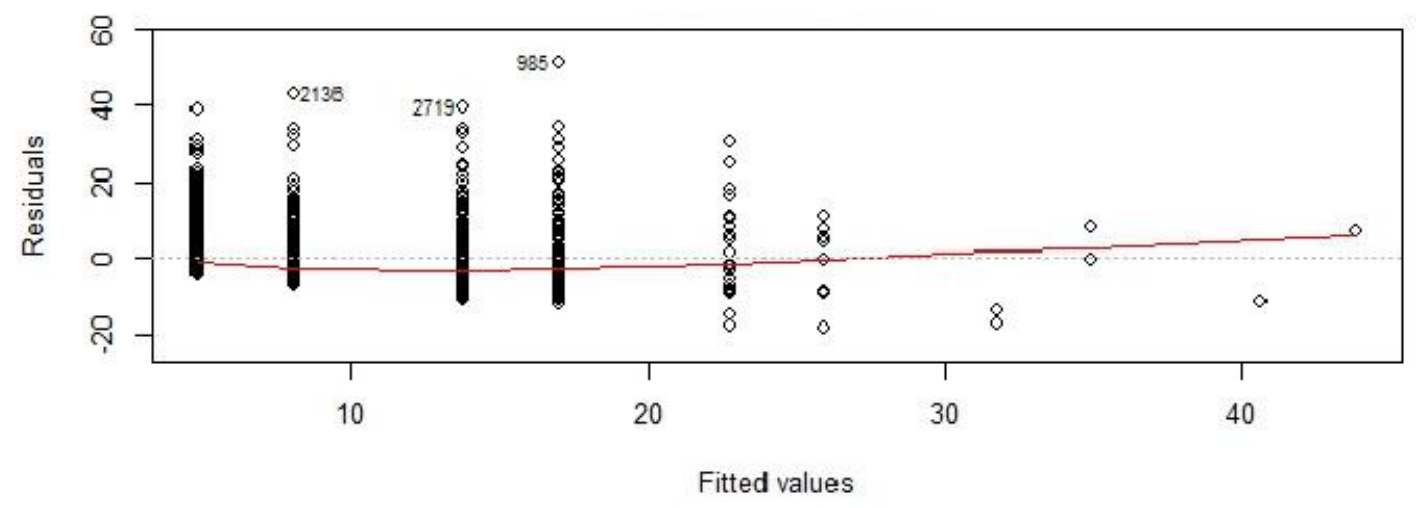

Fig.3 Residuals plots against the model fit the data.
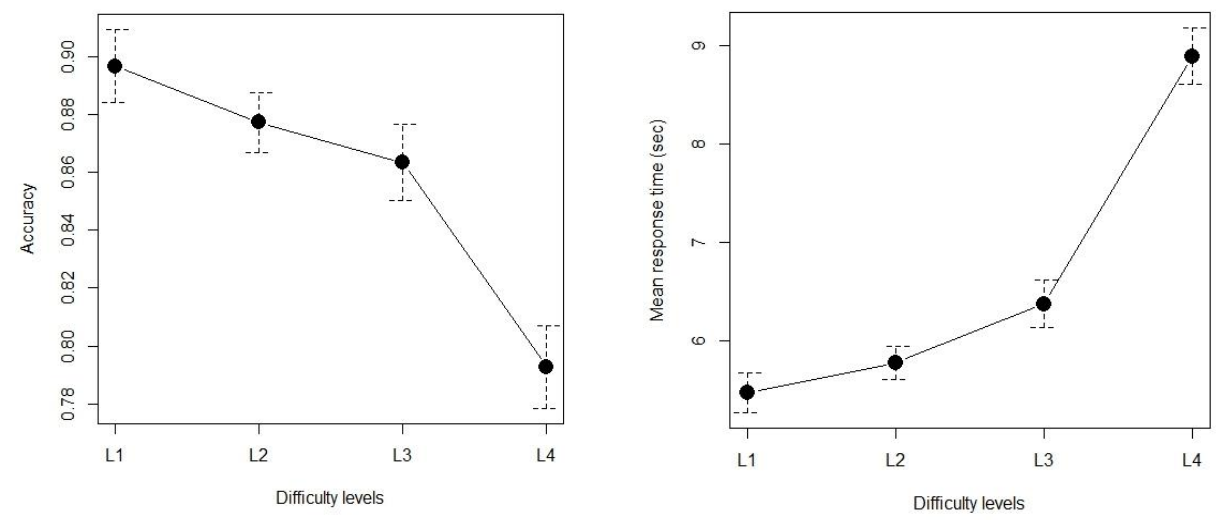

Fig. 4. The performance of the difficulty levels in terms of accuracy and mean response time. Standard error bars represent \pm standard error of the mean.

\subsection{The effect of the negative responses}

The results in Table 1 and Fig. 5 show that the mean time for incorrect response trials was always higher than the mean time for correct response trials. Then, we concluded that the positive responses were faster than the negative responses. There are two justifications to explain this finding: First, our application rewarded the correct responses, and therefore accuracy is emphasized (Ratcliff \& Rouder, 1998). Second, in case of incorrect response, the entire memory set must be scanned while the student evaluates the trial (Cowan, 1997). Table 1 provides an indication that the incorrect responses have significantly affected the overall performance of students with ASD. 


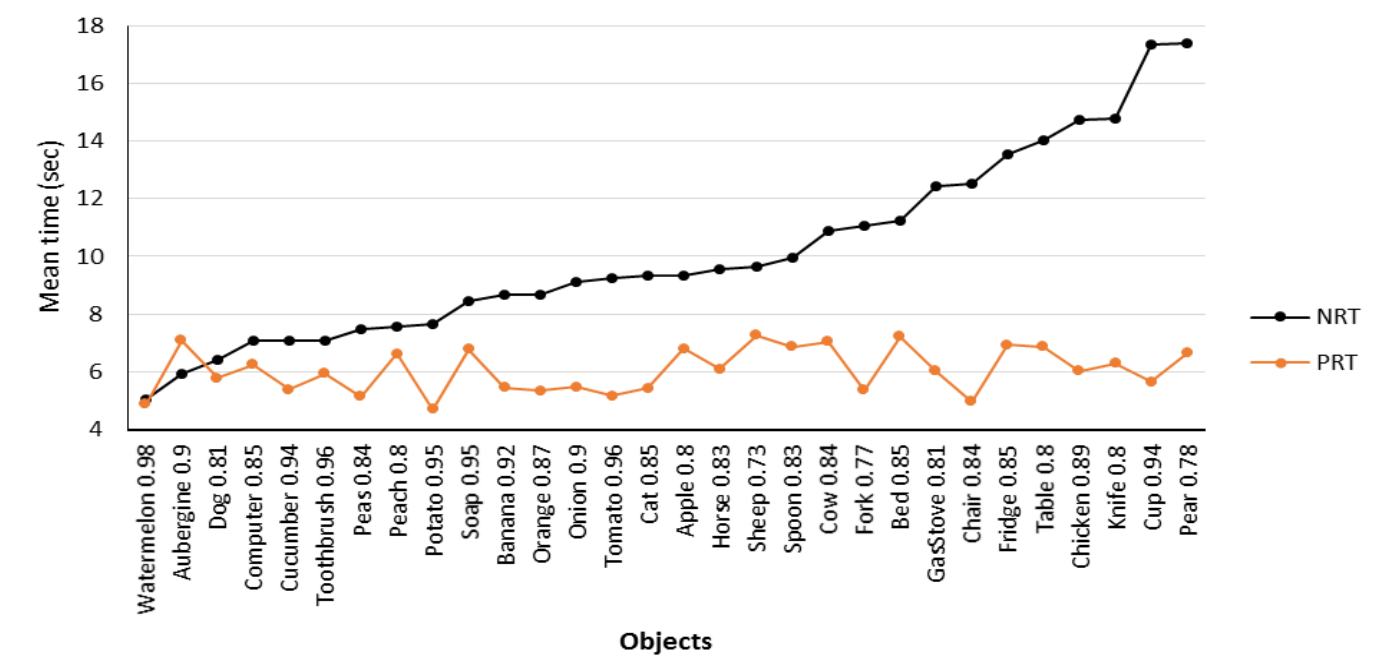

Fig. 5. The mean time for correct and incorrect response trials. The percentage beside the object's name indicates to the accuracy of that object.

\subsection{The effect of the location of object's image}

The location of object's image in a trial was classified into a set of four directions (UpRight, UpLeft, DownRight, and DownLeft). We used one-way ANOVA to test the significant differences in categorical and continuous variables. The significant main effect of the chosen location in trials, $F(3,308)=377.8$; $\mathrm{p}<.000$, demonstrated that the location manipulations had a differential influence on the response correct. However, the location manipulations did not influence the correct response time, $F(2,26)=$ $0.212 ; p=0.809$. Thus, the location of object's image in a trial should be uniformly distributed because the location has affected the student's responses. Analyzing the chosen location results, we noted that the students tended to select the location DownRight for negative responses more than other options. This finding was confirmed by the largest number of errors at this location (see Fig. 6a). In addition, the location DownRight got higher percentage of AR (see Fig. 6b). This was not sufficient to decide about the way the student followed the images' locations. Future research may include eye trackers to study eye movements during the trial.
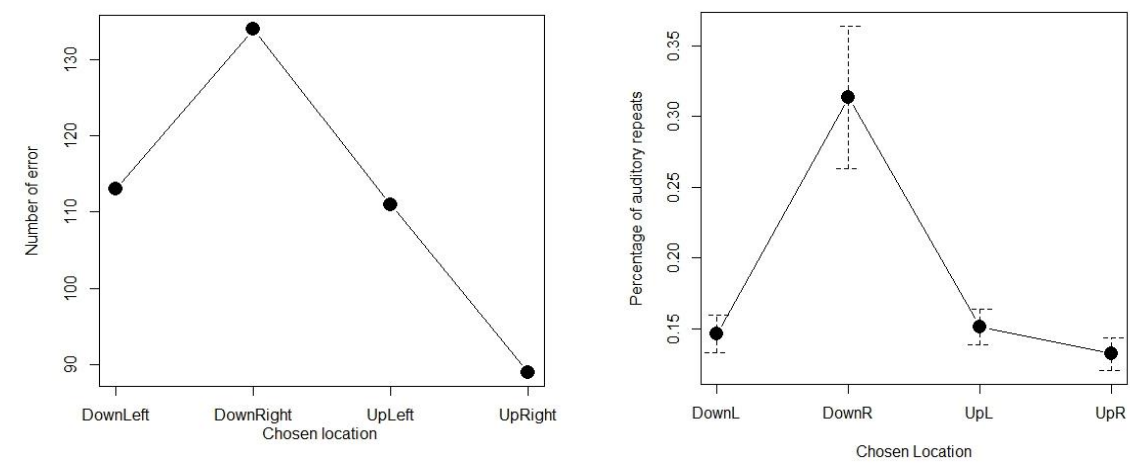

Fig. 6. a) Chosen location vs. number of errors b) Chosen location vs. percentage of auditory repeats

\subsection{The familiarity of categories}

The mean performance of all categories is presented in Table 2. One-way ANOVA calculated to assess whether differences existed in the accuracy and RT scores across the five groups of categories indicated a statistically significant difference. There were significant differences across category groups in accuracy means $(F(4,31)=5.337 ; p<.0002)$. Results also evidenced a significant differences between means of category's RTs as determined by one-way ANOVA $(F(4,31)=4.986 ; p$ $<.0005)$. Since some categories were better in accuracy and the others were better in response time, IES was used to determine the categories with better performance. IES scores in Table 2 demonstrated that category "vegetables" was the most familiar to our sample of students, while the 
"animals" and "furniture" categories were the least familiar. The tools and fruits were in the middle with approximately equal IES scores. The reason is that the students see these categories (vegetables, fruits and tools) as an integral part of their daily life, and so they become more familiar than the other categories. The confusion matrices were created between the true objects and the learned objects in each category for the students' responses (see Fig. 7). All correct answers are located in the diagonal of the matrix. Most of the off-diagonal elements of confusion matrix are either zero or have a considerably lower values compared to the diagonal elements. A confusion matrix for "vegetables" category was with less similarities off-diagonal entries while the similarities were more with higher values for other categories. For animals, the students usually learn animal's category by means of pictures not in real world. It is difficult for students to learn about the animals this way. Moreover, learning animals through pictures may influence students' conceptual knowledge of animals (Ganea, Canfield, Simons-Ghafari, \& Chou, 2014). Concerning furniture, they have different shapes, patterns, sizes and colors. Due to multiple differences, the students may be confused about how to choose the correct answer.

Table 2. The overall performance of categories. Standard error of the mean are given in parentheses.

\begin{tabular}{|l|l|l|l|l|l|l|l|}
\hline Category & $\begin{array}{l}\text { Accuracy } \\
(\%)\end{array}$ & $\begin{array}{l}\text { RT } \\
(\mathrm{sec})\end{array}$ & $\begin{array}{l}\text { PRT } \\
(\mathrm{sec})\end{array}$ & $\begin{array}{l}\text { NRT } \\
(\mathrm{sec})\end{array}$ & $\begin{array}{l}\text { IES } \\
(\mathrm{sec})\end{array}$ & $\begin{array}{l}\text { AR } \\
(\%)\end{array}$ & $\begin{array}{l}\text { No of } \\
\text { trials }\end{array}$ \\
\hline Animals & $0.822(0.016)$ & $6.881(0.267)$ & 6.256 & 9.775 & 7.606 & 0.143 & 580 \\
\hline Fruits & $0.853(0.014)$ & $6.665(0.251)$ & 5.951 & 10.809 & 6.976 & 0.184 & 640 \\
\hline Furniture & $0.832(0.013)$ & $7.320(0.297)$ & 6.393 & 11.914 & 7.683 & 0.183 & 673 \\
\hline Tools & $0.865(0.014)$ & $6.705(0.265)$ & 5.894 & 11.909 & 6.813 & 0.128 & 623 \\
\hline Vegetables & $0.908(0.012)$ & $5.713(0.195)$ & 5.533 & 7.487 & 6.096 & 0.108 & 574 \\
\hline
\end{tabular}

\subsection{Difficulty of recognizing the objects}

Fig. 8 shows that IES for the objects and a lower IES score means better performance. We concluded that the five objects that can easily to recognized are: potato, watermelon, tomato, cucumber and banana. These objects have very small similarities with values less than 0.03 (see Fig. 7). We noted that all of them are edible and have distinctive color or shape. The five most difficult objects are sheep, table, pear, apple and bed. It is not usual for the students to see the sheep in their daily life. But the cat and chicken can be seen in their real life. Pear, peach and apple have high similarities in shape and color. Sheep and cow also have high similarity in shape (see Fig. 7).

Vegetables

\begin{tabular}{|l|c|c|c|c|c|c|}
\hline & Aubergine & Cucumber & Onion & Peas & Potato & Tomato \\
\hline Aubergine & 0.89 & 0.02 & 0.04 & 0.03 & 0.00 & 0.03 \\
\hline Cucumber & 0.00 & 0.94 & 0.02 & 0.02 & 0.00 & 0.01 \\
\hline Onion & 0.02 & 0.03 & 0.90 & 0.02 & 0.02 & 0.00 \\
\hline Peas & 0.04 & 0.05 & 0.04 & 0.83 & 0.01 & 0.03 \\
\hline Potato & 0.00 & 0.03 & 0.00 & 0.02 & 0.95 & 0.00 \\
\hline Tomato & 0.01 & 0.00 & 0.02 & 0.00 & 0.00 & 0.96 \\
\hline
\end{tabular}

Fruits

\begin{tabular}{|l|c|c|c|c|c|c|}
\hline & Apple & Banana & Orange & Peach & Pear & Watermelon \\
\hline Apple & 0.80 & 0.02 & 0.03 & 0.07 & 0.05 & 0.03 \\
\hline
\end{tabular}


IJAEDU- International E-Journal of Advances in Education, Vol. 2, Issue 4, April 2016

\begin{tabular}{|l|l|l|l|l|l|l|} 
Banana & 0.01 & 0.92 & 0.02 & 0.01 & 0.03 & 0.01 \\
\hline Orange & 0.03 & 0.02 & 0.87 & 0.04 & 0.03 & 0.01 \\
\hline Peach & 0.05 & 0.01 & 0.07 & 0.80 & 0.05 & 0.01 \\
\hline Pear & 0.06 & 0.04 & 0.03 & 0.06 & 0.78 & 0.03 \\
\hline Watermelon & 0.00 & 0.00 & 0.01 & 0.01 & 0.00 & 0.98 \\
\hline
\end{tabular}

Animals

\begin{tabular}{|l|c|c|c|c|c|c|}
\hline & Cat & Chicken & Cow & Dog & Horse & Sheep \\
\hline Cat & 0.85 & 0.04 & 0.02 & 0.08 & 0.00 & 0.01 \\
\hline Chicken & 0.00 & 0.89 & 0.03 & 0.03 & 0.02 & 0.04 \\
\hline Cow & 0.04 & 0.01 & 0.84 & 0.04 & 0.03 & 0.03 \\
\hline Dog & 0.03 & 0.03 & 0.08 & 0.81 & 0.02 & 0.03 \\
\hline Horse & 0.03 & 0.05 & 0.02 & 0.03 & 0.84 & 0.02 \\
\hline Sheep & 0.03 & 0.07 & 0.13 & 0.04 & 0.00 & 0.73 \\
\hline
\end{tabular}

Furniture

\begin{tabular}{|l|c|c|c|c|c|c|}
\hline & Bed & Chair & Computer & Fridge & GasStove & Table \\
\hline Bed & 0.85 & 0.05 & 0.01 & 0.04 & 0.04 & 0.02 \\
\hline Chair & 0.03 & 0.84 & 0.03 & 0.05 & 0.02 & 0.03 \\
\hline Computer & 0.03 & 0.03 & 0.85 & 0.03 & 0.05 & 0.01 \\
\hline Fridge & 0.01 & 0.05 & 0.01 & 0.85 & 0.07 & 0.02 \\
\hline GasStove & 0.02 & 0.07 & 0.06 & 0.03 & 0.81 & 0.02 \\
\hline Table & 0.04 & 0.04 & 0.02 & 0.04 & 0.06 & 0.80 \\
\hline
\end{tabular}

Tools

\begin{tabular}{|l|c|c|c|c|c|c|}
\hline & Cup & Fork & Knife & Soap & Spoon & Toothbrush \\
\hline Cup & 0.94 & 0.01 & 0.01 & 0.01 & 0.01 & 0.01 \\
\hline Fork & 0.04 & 0.77 & 0.07 & 0.03 & 0.05 & 0.03 \\
\hline Knife & 0.01 & 0.06 & 0.80 & 0.03 & 0.07 & 0.03 \\
\hline Soap & 0.01 & 0.01 & 0.01 & 0.96 & 0.00 & 0.01 \\
\hline Spoon & 0.04 & 0.06 & 0.03 & 0.01 & 0.83 & 0.03 \\
\hline Toothbrush & 0.00 & 0.01 & 0.01 & 0.01 & 0.00 & 0.96 \\
\hline
\end{tabular}

Fig. 7. Confusion matrix for each category and the highlighted off-diagonal elements indicate there is some significant similarity between two objects in a category.

\subsection{Guidance for developing tablet applications}

This investigation could not be implemented using traditional approaches of teaching. Using the tablet helped us to provide a large number of pictures while teaching. These pictures were presented to students in an easy and interesting way. Tablets also support web-based software and touch screen offers multiple advantages to students. Moreover, the accuracy of the collected data could not be achieved through a paper-based method. Due to these features of tablet PCs, we suggest that tablets can be an effective instructional tool to enhance teaching and learning for students with ASD. Based 
on our findings, we offer suggestions for developing tablet applications to teach students with ASD. The following should be considered in designing future applications:

- The screen should focus on the objects' images in a trial and should not include many largesize icons or buttons in order to maintain the student's attention.

- When asking about particular object in a trial, the other three objects should be selected from the same category.

- Distribution of the location of object's image for a trial should be uniform.

- It is possible to stop and pause the application during the session, if the student get tired or bored.

- The images of a trial should be uniform in resolution and size.

- The investigation may start with a low-level difficulty and work toward a high-level difficulty.

- The images used for teaching and assessment conditions of a session should be different.

- The participants might either be required to have a set of prerequisite fine tablet skills or be provided with an initial independent set of sessions to increase the tablet usage skills.

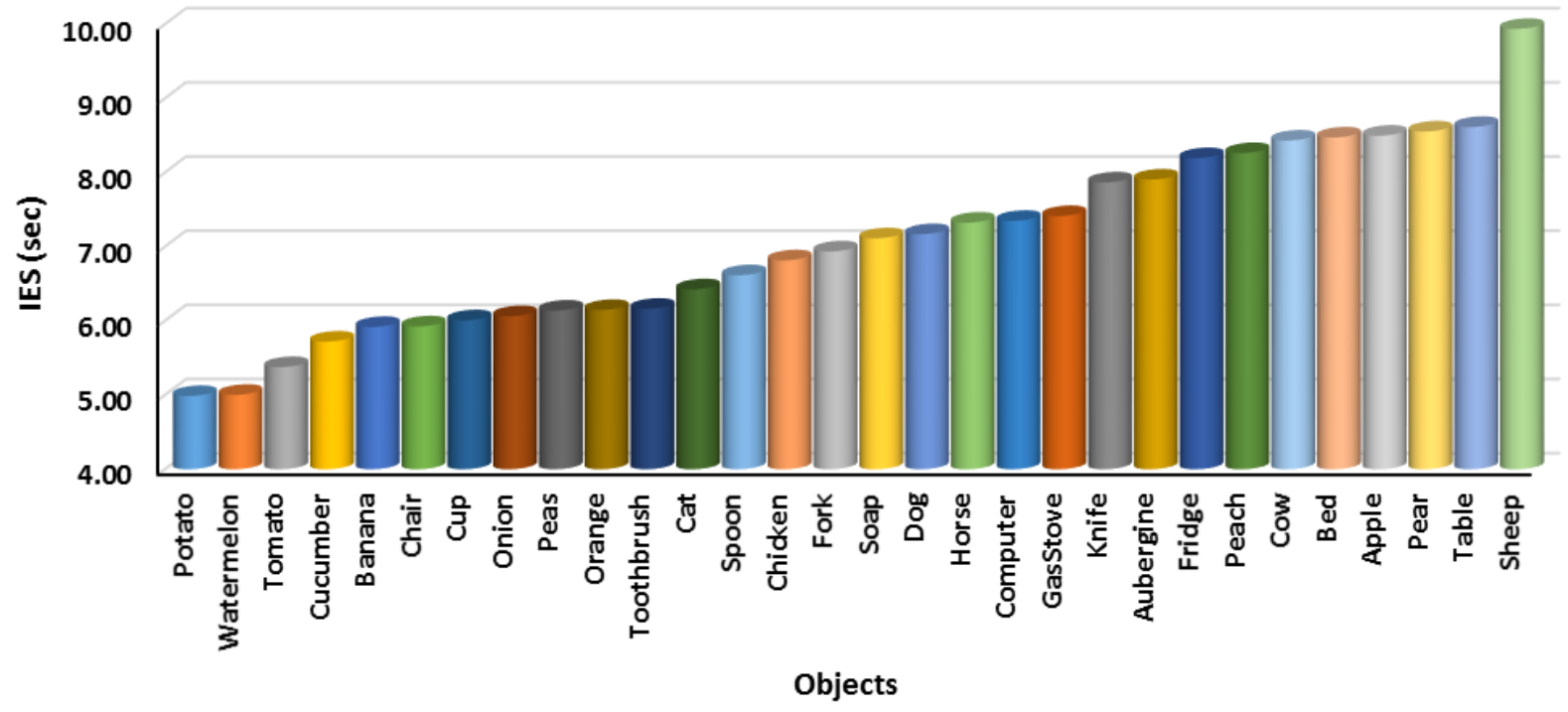

Fig. 8. Objects vs. inverse efficiency score (IES).

\section{CONCLUSION}

In this paper we present an analysis and visualization of the data collected using a web application during the learning sessions. The results of the analysis were interpreted and provided us a better understanding about object categorization for students with ASD. A number of factors influence a student's response including familiarity of categories, difficulty levels, the location of object's image and similarities with the other objects. For the empirical results of the study, we also present justifications to explain these results. The findings help us enhance the teaching process and monitor student's learning progress and then personalize learning for each student.

\section{REFERENCE LIST}

Alberto, P. A., \& Troutman, A. C. (2012). Applied behavior analysis for teachers. Pearson Higher Ed.

Alpaydin, E. (2014). Introduction to machine learning. MIT press.

American Psychiatric Association. (2013). Diagnostic and Statistical Manual of Mental Disorders (DSM-5). American Psychiatric Pub. 
Bruyer, R., \& Brysbaert, M. (2011). Combining speed and accuracy in cognitive psychology: Is the inverse efficiency score (IES) a better dependent variable than the mean reaction time (RT) and the percentage of errors (PE)? Psychologica Belgica, 51(1), 5.

Cowan, N. (1997). Attention and memory. Oxford University Press.

Doenyas, C., Şimdi, E., Özcan, E. Ç., Çataltepe, Z., \& Birkan, B. (2014). Autism and tablet computers in Turkey: Teaching picture sequencing skills via a web-based iPad application. International Journal of Child-Computer Interaction, 2(1), 60-71.

Eldevik, S., Ondire, I., Hughes, J. C., Grindle, C. F., Randell, T., \& Remington, B. (2013). Effects of computer simulation training on in vivo discrete trial teaching. Journal of Autism and Developmental Disorders, 43(3), 569-578.

Fox, J., \& Carvalho, M. S. (2012). The RcmdrPlugin. survival package: Extending the R Commander interface to survival analysis. Journal of Statistical Software, 49(7), 1-32.

Ganea, P. A., Canfield, C. F., Simons-Ghafari, K., \& Chou, T. (2014). Do cavies talk? The effect of anthropomorphic picture books on children's knowledge about animals. Frontiers in Psychology, 5. Retrieved from http://www.ncbi.nlm.nih.gov/pmc/articles/PMC3989584/

Gastgeb, H. Z., Dundas, E. M., Minshew, N. J., \& Strauss, M. S. (2012). Category formation in autism: can individuals with autism form categories and prototypes of dot patterns? Journal of Autism and Developmental Disorders, 42(8), 1694-1704.

Gastgeb, H. Z., Strauss, M. S., \& Minshew, N. J. (2006). Do individuals with autism process categories differently? The effect of typicality and development. Child Development, 77(6), 1717-1729.

Horner, R. H., Carr, E. G., Halle, J., McGee, G., Odom, S., \& Wolery, M. (2005). The use of singlesubject research to identify evidence-based practice in special education. Exceptional Children, 71(2), 165-179.

Jordan, R. (2013). Autism with severe learning difficulties. Souvenir Press.

Kagohara, D. M., Sigafoos, J., Achmadi, D., O'Reilly, M., \& Lancioni, G. (2012). Teaching children with autism spectrum disorders to check the spelling of words. Research in Autism Spectrum Disorders, 6(1), 304-310.

Klinger, L. G., \& Dawson, G. (1995). A fresh look at categorization abilities in persons with autism. In Learning and cognition in autism, 119-136.

O'Malley, P., Lewis, M. E. B., \& Donehower, C. (2013). Using Tablet Computers as Instructional Tools to Increase Task Completion by Students with Autism. Online Submission, Paper Presented at the Annual Meeting of the American Educational Research Association (San Francisco, CA, Apr 27-May 1, 2013).

Ratcliff, R., \& Rouder, J. N. (1998). Modeling response times for two-choice decisions. Psychological Science, 9(5), 347-356.

Smith, B. R., Spooner, F., \& Wood, C. L. (2013). Using embedded computer-assisted explicit instruction to teach science to students with autism spectrum disorder. Research in Autism Spectrum Disorders, 7(3), 433-443.

Smith, V., \& Sung, A. (2014). Computer Interventions for ASD. In Comprehensive guide to Autism (pp. 2173-2189). Springer. Retrieved from http://link.springer.com/10.1007/978-1-4614-4788-7_134 